\title{
Comparison of Various Fingerprint Analysis Techniques
}

\author{
K. Uma* and E. Kavitha
}

Department of IT, VIT University, Vellore - 632014, Tamil Nadu, India; drumaphd@gmail.com

\begin{abstract}
Fingerprint pixy location unit not often of notable nice. They'll be degraded and corrupted with components of noise on account of many elements at the facet of versions in pores and skin and impression conditions. This degradation may cause a clearly very vital vary of spurious object being created and real object being left out. An important step in mastering the facts of fingerprint item is to reliably extract object from fingerprint images. Thus, it's a necessity to apply picture development techniques before object extraction to urge a masses of dependable estimate of object places. The purpose of this challenge is to implement a sequence of strategies for fingerprint picture development and object extraction. Experiments victimization each artificial take a glance at images and actual fingerprint snap shots place unit accustomed examine the overall performance of the implemented strategies. These strategies region unit then accustomed extract object from a pattern set of fingerprint pictures. By victimization the extracted object facts, preliminary experiments at the information of fingerprints can then be carried out a fingerprint photo won't always be published due to additives of noise that corrupt the readability of the ridge systems. This corruption may additionally arise as a consequence of versions in pores and skin and impression situations like scars, humidity, dust and non-uniform contact with the fingerprint seize tool.
\end{abstract}

Keywords: Correlation based Technique, Feature Extraction, Fingerprint, Fingerprint, Minutiae based Technique, Recognition Ridge based Technique.

\section{Introduction}

Fingerprint recognition is typically used in rhetorical science to hold up criminal investigations, and in biometric systems treasure civilian and business identification hardware ${ }^{10}$. Despite this current use of fingerprints, there has been little or no maths work done on the individuality of fingerprint trifle $\frac{19}{}$. Above all, the problem of what proportion trifle points got to be used for synchronal fingerprint sweetening is unresolved ${ }^{11}$. The fingerprint of a nonpublic is exclusive and remains unaffected over a period of time. A fingerprint is formed from a notation of the pattern of ridges on a finger. A ridge is apparent together curving section and a basin is that the region between two shut ridges. The trivia, that unit of measurement the native divergence inside the ridge flow pattern, provide the choices that unit of measurement used for recognition $^{3}$. Details treasure the kind, quite reading and web site of trifle unit of measurement taken into report once acting trifle extraction ${ }^{1}$. It specifies a set of choices for fingerprint identification that since then has been polished to include any styles of fingerprint choices ${ }^{-}$. However, most of these choices do not appear to be mostly used in fingerprint identification systems ${ }^{6}$. Instead the set of trifle varieties unit of measurement restricted into alone two varieties, ridge endings and bifurcations, as various styles of trifle could also be articulated in terms of these two feature varieties. Ridge endings unit of measurement the points where the ridge curve stops and bifurcations unit of measurement where a ridge splits from one path to two ways that at a Y-junction.

\section{Related Works}

\subsection{Minutiae based Technique}

Minutiae mostly primarily based algorithms depend upon the native divergence in the ridge go with the flow sample and are used once pattern size is vital as totally a tiny low

${ }^{*}$ Author for correspondence 
part of fingerprint image is needed for verification in trivialities primarily based systems ${ }^{17}$. It might be first-rate to use these algorithms wherever residence limits effect the utilization and operation of life science however this form of system desires pinnacle great of fingerprint photo. Additionally minutiae based totally technique wishes in depth pre-processing operation ${ }^{13}$. It's additionally should reduce again the quantity of fake trivialities incorrectly detected in hissing fingerprint pics?

\subsection{Correlation based Technique}

In this paintings, the sample fingerprint rectangular degree spoken due to the fact the initial fingerprint and so the take a look at fingerprint rectangular measure spoken because the secondary fingerprint ${ }^{18}$. The correlationbased totally fingerprint verification system first selects desired styles within the first fingerprint, makes use of sample matching to are seeking for out them within the secondary fingerprint, and compares the sample positions of each fingerprints ${ }^{14}$. There are some challenges love call for of extra operational power for real time applications and dealing snap shots with larger rotations and risk of finding the wrong example position that degrades the matching overall performance ${ }^{16}$.

\subsection{Ridge based Technique}

Fingerprint matching supported minutiae alternatives every so often build declaration that the 2 fingerprints to be matched unit of dimension of approximately identical $\operatorname{size}^{15}$. However, this declaration is not legitimate in clever. Even fingerprints captured exploitation complete absolutely special completely distinctive entirely extraordinary scanners would possibly need unique length. Further photos with whole completely one-of-a-kind orientation might also fail to fit in trivialities-picture based strategies due to relative change in their minutiae places ${ }^{21}$. In turned fingerprint matching, it's hard to healthy trivia of footage as a consequence of because of movement, coordinate places of all the trivia factors unit of size changed. In partial fingerprint matching, it's similarly hard to in shape trivia of footage as a result of due to lacking a vicinity of the fingerprint, coordinate places of all of the minutiae factors unit of measurement changed ${ }^{5}$. And, trivialities primarily based matching algorithms do no longer perform nicely absolutely simply in case of little fingerprints that has solely a couple of trivialities. Moreover, reliable extraction of minutiae from poor quality fingerprints may be very difficult and registering trivialities example may be very hard. Further, designers of fingerprint popularity approaches explore for picks at the so much factor trivialities and thence, the foremost huge used severa approach introduced is Ridge based matching method ${ }^{7}$.

\section{Comparison Analysis}

Minutiae primarily based method first locates trivialities points and then maps their relative placement on the finger. Correlation based totally technique is ready to conquer some of the difficulties of the trivia primarily based method. Instead of simplest the usage of the minutiae vicinity, it without delay makes use of the grey level facts. Because of grey degree fingerprint image includes a whole lot richer, greater discriminatory fact's than most effective the trivialities places ${ }^{4}$. Ridge based approach is used even though features are spoiled or shortage of functions and deriving ridge records of an input fingerprint. The advantages and dies-blessings of diverse techniques which are proposed in this paper are proven in Table 1.

\subsection{Advantages and Dis-advantages}

Table 1. Pros and cons of finger print detection techniques

\begin{tabular}{|c|c|c|c|}
\hline s.no & Techniques & Advantages & Disadvantages \\
\hline 1 & $\begin{array}{l}\text { Minutiae } \\
\text { based } \\
\text { technique }\end{array}$ & $\begin{array}{c}\begin{array}{c}\text { 1. Query finger } \\
\text { print and every } \\
\text { fingerprint stored } \\
\text { in database }\end{array} \\
\text { 2. Used to facilitate } \\
\text { the further study } \\
\text { of the statistics of } \\
\text { fingerprints }\end{array}$ & $\begin{array}{l}\text { 1. Local ridge structure } \\
\text { cannot be completed. } \\
\text { 2. User acceptance is } \\
\text { very low. } \\
\text { It is time consuming. }\end{array}$ \\
\hline 2 & $\begin{array}{c}\text { Correlation } \\
\text { based } \\
\text { technique }\end{array}$ & $\begin{array}{l}\text { 1. No minutiae } \\
\text { can be extracted } \\
\text { reliable } \\
\text { 2. False and } \\
\text { missed minutiae } \\
\text { do not decrease } \\
\text { the matching } \\
\text { performance }\end{array}$ & $\begin{array}{l}\text { 1. Require the } \\
\text { precise location of a } \\
\text { registration point } \\
\text { 2. Affected by image } \\
\text { translation and } \\
\text { rotation } \\
\text { 3. Not capable of } \\
\text { dealing with rotations } \\
\text { of more than about to } \\
\text { degrees. }\end{array}$ \\
\hline 3 & $\begin{array}{c}\text { Ridge based } \\
\text { technique }\end{array}$ & $\begin{array}{c}\text { 1. The clarity of the } \\
\text { ridge structures } \\
\text { while reducing } \\
\text { noise }{ }^{2} \text {. }\end{array}$ & $\begin{array}{c}\text { 1. Provide a natural } \\
\text { representation } \\
\text { of fingerprint } \\
\text { imperfections such as } \\
\text { noise and corrupted } \\
\text { elements }\end{array}$ \\
\hline
\end{tabular}




\subsection{Comparison Analysis Result}

A coefficient of correlation is an arithmetical measure of how a great deal one variety may be predictable to be prompted with the aid of adjustments in another. It is intently related to covariance. Digital Image Correlation is a full-area picture evaluation technique, primarily based on gray fee virtual photos which can decide the curve and the displacements of an object below load in three dimensions $^{12}$. Digital picture correlation (DIC) technique have been increasing in reputation, specifically in micro- and nano-scale mechanical checking out programs due to its corresponding ease of implementation and use $\mathrm{e}^{20}$. It is best for template matching. Large volumes of fingerprints are amassed and saved day by day in a wide variety of programs along with forensics; get right of entry to manage, and driver license registration. The extracted trivia are counted using bendy in shape set of rules and saved the .Mat document. Comparison is made between the question fingerprint and each fingerprint stored in database if the matching score is extra than the predefined threshold then the 2 fingerprints are stated to be of identical man or woman.

\subsection{Experimental Graph}

Table 2. Shows the average of percentage matching of individual person

\begin{tabular}{|c|c|}
\hline Name of the person & $\begin{array}{c}\text { Average of \% matching of individual } \\
\text { person }\end{array}$ \\
\hline Person 1 & 80 \\
\hline Person 2 & 70 \\
\hline Person 3 & 80 \\
\hline Person 4 & 78 \\
\hline Person 5 & 72 \\
\hline Person 6 & 88 \\
\hline Person 7 & 94 \\
\hline Person 8 & 87 \\
\hline Person 9 & 77 \\
\hline
\end{tabular}

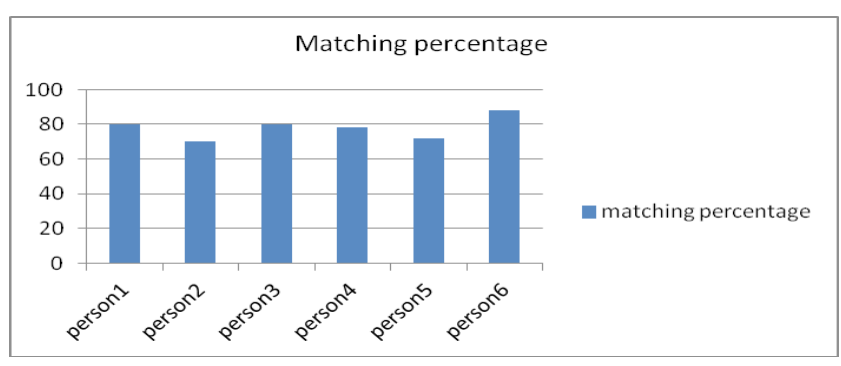

Figure 1. Graph showing percentage of matching individual fingerprint.
Table 3. Shows comparing the original fingerprint and altered fingerprint and then calculate the individual matching rate

\begin{tabular}{|c|c|c|}
\hline Type of Fingerprint & $\begin{array}{c}\text { Number of } \\
\text { Fingerprint samples }\end{array}$ & $\begin{array}{c}\text { Average Matching } \\
\text { Rate in \% }\end{array}$ \\
\hline Original Fingerprint & 10 & 100 \\
\hline Altered Fingerprint & 40 & 79.5 \\
\hline
\end{tabular}

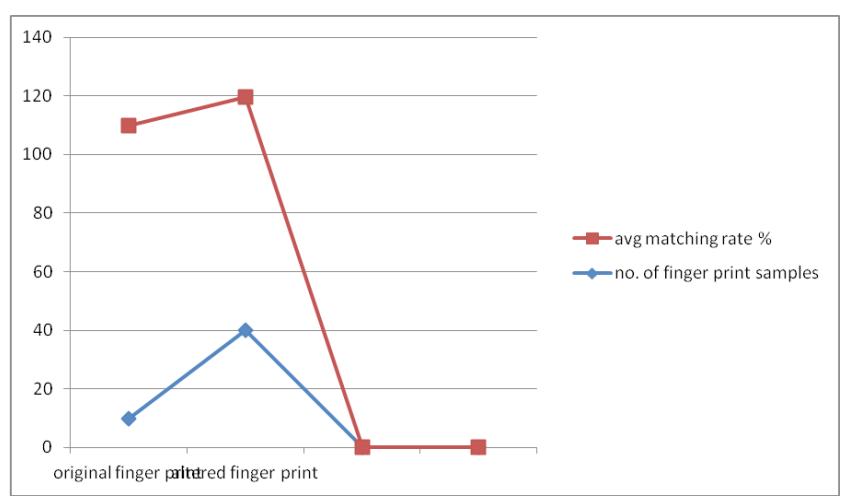

Figure 2. Graph showing average matching rate of altered fingerprint and normal fingerprint.

\section{Conclusion}

In this paper we use 3 techniques minutiae based totally technique, correlation based techniques and Ridge primarily based methods. The trivialities validation algorithm indicates that this extra put up processing degree is powerful in disposing of various sorts of fake trivia structures. Results of correlation calculation strategies in template matching, it's miles inferred that the great approach is Correlation Coefficient based totally template matching and also this method indicates that the coefficient values of effectively matched photo is without a doubt better than those coefficient values of mismatched pictures (impostors). A large margin separates the real and fake tested dataset; lowering the chances of false recognized as imposter

\section{References}

1. Cao S, Snavely N. Graph based discriminative learning for location recognition. CVPR. 2013. Crossref

2. Carlone L, Alcantarilla PF, Chinu HP, Kira Z, Del-laert F. Mining structure format for smart bundle adjustment. BMVC. 2014.

3. van Leeuwen M. Interactive data exploration using pattern mining. International Journal on Artificial Intelligence Tools. 2014; 1-14. 
4. Hariharan B, Malik J, Ramman D. Discriminative de-correlation for clustering and classification. 2012.

5. Wieclaw L. A minutiae-based matching algorithms in fingerprint recognition system. Journal of Medical Informatics and Technologies. 2009; 13:1-8.

6. Mandi RM, Lokhande SS. Rotation-invariant fingerprint identification system. IJECCT. 2012 Jul; 2(4):145-9.

7. Singh R, Shah U, Gupta V. Fingerprint recognition. Department of Computer Science and Engineering, Indian Institute of Technology, Kanpur. Computer Vision and Image Processing (CS676).

8. Diefenderfer GT. Fingerprint recognition. Naval Postgraduate School Monterey, California.

9. Dadlani C, Passi AK, Sahota H, Kumar MK. Fingerprint recognition using minutiae based feature. As part of EE851: Biometrics.

10. Mary Lourde R, Khosla D. Fingerprint identification in biometric security systems. International Journal of Computer and Electrical Engineering. 2010 Oct; 2(5):852-5.

11. Fingerprint image enhancement and minutiae extraction by Raymond Thai.

12. Lee HC, Gaensslen RE. Advances in fingerprint technology. New York: Elsevier; 1991.

13. Gonzalez RC, Woods RE. Digital image processing. Pearson Education Asia. 2002
14. Hong JL, Boler R. Online fingerprint verification. IEEE Tran. 1997.

15. Jain AK, Prabhakar S, Hong L, Pankanti S. Filter bankbased fingerprint matching. IEEE Transactions on Image Processing. 2000; 9:846-59. PMid: 18255456. Crossref

16. Kovacs-Vajna ZM. A fingerprint verification system based on triangular matching and dynamic time warping. IEEE Transactions on Pattern Analysis and Machine Intelligence. 2000: 20(11):1266-76. Crossref

17. Maio D, Maltoni D, Cappelli R, Wayman JL, Jain AK. FVC2004: Third fingerprint verification competition. Proceedings of International Conference on Biometric Authentication, LNCS 3072; Hong Kong. 2004 Jul. p. 1-7.

18. Maltoni D, Maio D, Jain AK, Prabhakar S. Handbook of fingerprint recognition. Springer. 2003.

19. Pankanti S, Prabhakar S, Jain AK. On the individuality of fingerprints. IEEE Transactions on Pattern Analysis and Machine Intelligence, 2002; 24(8):1010-25. Crossref

20. Pratt WP. Digital image processing. John Willey and Sons. 2001. Crossref

21. Brown LG. A survey of image registration techniques. ACM Computing Surveys. 1992 Dec; 24(1):326-76. 